\title{
Antioxidant and Antidiabetic Activity of Aqueous Extract of Myrtus Communis L. Berries on Streptozotocin-Induced Diabetic Rats
}

\author{
Galip Mesut Demir ${ }^{1}$, Mine Gulaboglu ${ }^{1}$, Ahmet Gokhan Aggul ${ }^{2}$, \\ Nurcan Kilic Baygutalp ${ }^{1}$, Dogukan Canayakin ${ }^{1}$, Zekai Halici ${ }^{3}$, Halis Suleyman ${ }^{4}$ \\ ${ }^{I}$ Ataturk University, Faculty of Pharmacy, Department of Biochemistry, Erzurum, TURKEY \\ ${ }^{2}$ Ibrahim Cecen University, Faculty of Pharmacy, Department of Biochemistry, Agri, TURKEY \\ ${ }^{3}$ Ataturk University, Faculty of Medicine, Department of Pharmacology, Erzurum, TURKEY \\ ${ }^{4}$ Erzincan University, Faculty of Medicine, Department of Pharmacology, Erzincan, TURKEY
}

\begin{abstract}
Background: Myrtus communis L. (MC) is widely used as an antidiabetic plant in folk medicine. This study aimed to analyze the possible antidiabetic and hepatoprotective effects of MC berries in streptozotocin (STZ)induced diabetic rats.

Methods: The study used a total of 30 rats in 6 groups of 5. DM was induced with a single injection of 40 $\mathrm{mg} / \mathrm{kg} \mathrm{STZ}$, after which 3 of the groups were administered 250, 500 or $1000 \mathrm{mg} / \mathrm{kg}$ aqueous extract of MC berries by oral gavage for 14 days. Alanine aminotransferase (ALT), alkaline phosphatase (ALP), and aspartate aminotransferase (AST) levels were determined in the serum and glutathione (GSH), malondialdehyde (MDA) levels and superoxide dismutase (SOD) activity were determined in the liver tissue of the rats.

Results: MC administration provided a significant reduction in the altered serum glucose, AST, ALT and ALP levels in all the diabetic groups. MC extract showed significant antioxidant activity by increasing SOD activity and GSH level and reducing MDA levels in diabetic rats compared to the control group ( $p<0.05)$. Serum AST, $A L T$ and ALP levels were reduced by MC administration in all the diabetic groups. The maximum hypoglycemic and antioxidant effects were observed at $1000 \mathrm{mg} / \mathrm{kg}$ dose of MC.
\end{abstract}

Conclusion: The results demonstrated that aqueous extract of Myrtus communis L. has antidiabetic and antioxidant activity. These results confirm the traditional usage of this plant as an antidiabetic herb.

Keywords: Antioxidant, berries, liver, Myrtus communis L., Type II diabetes

\section{Introduction}

Diabetes mellitus (DM) is a chronic metabolic disorder affecting many people around the world. The disease is characterized by altered blood glucose levels, carbonhydrate, lipid and protein metabolism defects and complications including hepatopathy, nephropathy and neuropathy. As the disease has deleterious effects on the health status of individuals and large numbers are affected, the socio-economic consequences of the disease can impact the productivity of nations ${ }^{1}$.

A disproportion between reactive oxygen species generation and free radical scavenging systems causes oxidative stress in the body. In DM, reactive oxygen species (ROS) production is elevated and the resulting oxidative stress is closely related with DM complications ${ }^{2}$. Superoxide anion, MDA and oxide glutathione are indicators of oxidative stress. Chronic accumulation of ROS in hyperglycemia plays a pivotal role in the development of liver injury. Antioxidant drugs and plants with antioxidant properties have been reported to be benefical in reducing or recovering DM-related liver injury ${ }^{3}$.Therefore, there is growing interest in herbal medicine for the treatment of $\mathrm{DM}^{4}$. Myrtus communis L. (MC) is an endemic plant in the Mediterranean region, which is widely grown and used in west and south Anatolia. Various parts of MC are used in folk medicine. In vitro and animal studies have demonstrated a wide range of activities, including antidiabetic, anti-inflammatory, analgesic, antiviral, antimutagenic and cardiovascular effects ${ }^{5}$.

To date, animal studies have been conducted to demonstrate the antidiabetic effects of MC by inducing Type II DM either with streptozotocin (STZ) or alloxan ${ }^{4,6,7}$. Although there is considerable evidence about the antidiabetic effects of MC, the underlying mechanism of the hypoglycemic effect is unclear. Some researchers have suggested that the effects of MC on glucose metabolism can be summarized as activation of degradation pathways and inhibition of production pathways ${ }^{4}$.

Thus, MC can be considered as a possible candidate antidiabetic agent due to its high antioxidant and hepatoprotective effects. This study was designed to investigate the possible antidiabetic effects of MC berries on rats in a diabetic condition induced by STZ. 


\section{Plant material and extract preparation}

\section{Methods}

The botanical identification was made according to international identification methods by a professional botanist. The berries were mechanically powdered by liquid nitrogen, and extracted with pure water six times. The obtained extracts were filtered and combined, and the solvent was evaporated. The extract was diluted in pure water and administered to the rats with intragastric gavage.

\section{Experimental Animals}

The study was approved by and conducted in accordance with the local Institutional Animal Care and Use Committee, under protocol no. 128. All animals were housed in facilities approved by international guidelines. During the experimental period, all rats received a normal chow diet and drinking water ad libitum.

\section{Induction of diabetes mellitus}

STZ was dissolved in citrate buffer $(0.1 \mathrm{~mol} / \mathrm{L}, \mathrm{pH}: 4.5)$. Type II Diabetes mellitus was induced with STZ solution at a single dose of $40 \mathrm{mg} / \mathrm{kg}$ body weight. Three days after DM inducement, administration of aqueous extract of MC berries began and lasted for 14 days. Blood samples were obtained from the tail vein and rats with a glucose level $\geq 200 \mathrm{mg} / \mathrm{dl}$ were accepted as DM and included in the study ${ }^{8}$.

\section{Experimental Design}

A total of thirty 6-week-old male Albino Wistar rats (weighing 200-220 g) were randomly divided into 6 groups of 5: Group I = normal control; Group II = DM control; Group III = $1000 \mathrm{mg} / \mathrm{kg}$ MC extract; Group IV =DM+250 mg/kg MC extract; Group V = DM+500 mg/kg MC extract; Group VI = DM+1000 mg/kg MC extract. The animals were sacrificed by cervical dislocation. Cardiac blood samples were obtained and the livers were removed.

\section{Serum Samples and Biochemical Tests}

Blood glucose levels were measured by a glucometer (Accu-Chek Active) and respective dry reagent test-strips based on the glucose oxidase technique. Serum aspartate aminotransferase (AST), alkaline phosphatase (ALP) and alanine aminotransferase (ALT) levels were measured using an automatic biochemical and immune-enzyme analyzer (GBG ChemWell 2990,USA) with commercially availabe enzyme kits.

\section{Production of liver homogenate and measurement of oxidative stress parameters}

The liver tissues were ground with liquid nitrogen in a mortar. The tissues were treated with HEPES buffer for superoxide dismutase (SOD) and RIPA buffer for malondialdehyde (MDA) measurement and then homogenized on ice by an Ultra-Turrax homogenizer at $9500 \mathrm{rpm}$. The supernatans obtained from centrifugation of homogenates were used to determine SOD and MDA levels with ELISA kits produced for rats (Cayman Chemical and TBARS Assay STA-330 respectively).

The reduced glutathione (GSH) levels in the liver tissues were determined according to the method of Sedlak and Lindsay9. For this assay, $2 \mathrm{~mL}$ of $50 \mathrm{mM}$ Tris- $\mathrm{HCl}$ buffer containing 20mM EDTA and 0.2M sucrose, $\mathrm{pH} 7.5$ was used to homogenize the liver tissue. The homogenate was centrifuged at $4200 \mathrm{rpm}$ for 40 $\min$ at $4{ }^{\circ} \mathrm{C}$, and then the supernatant was used to determine GSH using 5.5-dithiobis (2-nitrobenzoic acid). GSH concentration was determined by spectrophotometer at $412 \mathrm{~nm}$. SOD activity and serum GSH and MDA levels were expressed as $\mathrm{U} / \mathrm{mg}$ tissue, $\mu \mathrm{M} / \mathrm{mg}$ tissue, and $\mu \mathrm{M} / \mathrm{mg}$ tissue respectively.

\section{Chemicals}

Streptozotocin (C8H15N3O7) (STZ) was obtained from Sigma Aldrich (Sigma, USA). All other chemicals and analytical grade solvents were of the highest quality available and were purchased from Merck Chemicals (Germany). Purified double distilled water was used for the analytical procedures.

\section{Statistical analysis}

Statistical analysis was performed using the SPSS 20.0 program (SPSS Inc., Chicago, IL, USA). Data were presented as mean and standard deviation (mean $\pm \mathrm{SD}$ ). The Kolmogrov-Smirnov test was used to test the normality of data. Post-comparisons were carried out with Fisher's least significant difference (LSD) test for post hoc analysis. Statistical significance was accepted at a level of $\mathrm{p} \leq 0.05$ in $95 \%$ confidence of interval. 


\section{Results}

Effects of MC berries extract on blood glucose levels

The blood glucose levels of the control, diabetic control and diabetic treated with MC extract groups are given in Table 1. Blood glucose levels were significantly and 3.4 times higher in the diabetic model (diabetic control) group compared to the control group $(\mathrm{p}<0.001)$. Although blood glucose levels were slightly higher in the MC extract only $(1000 \mathrm{mg} / \mathrm{kg})$ administrated group compared to the control group, this elevation was not significant ( $>0.05$ ). The blood glucose levels were significantly decreased by oral administration of all doses $(250 \mathrm{mg} / \mathrm{kg}, 500 \mathrm{mg} / \mathrm{kg}, 1000 \mathrm{mg} / \mathrm{kg}$ ) of aqueous extract of $\mathrm{MC}(\mathrm{p}<0.05, \mathrm{p}<0.05, \mathrm{p}<0.001$ respectively) (Table 1). The $1000 \mathrm{mg} / \mathrm{kg}$ dose of MC extract was determined to be more effective than the other doses in reducing blood glucose levels.

\section{Effects of MC berries extract on liver enzymes}

Serum ALT, AST and ALP levels were significantly higher in the diabetic model (diabetic control) group compared to the control group ( $\mathrm{p}<0.01$ for all parameters). The oral administration of MC berries extract at $1000 \mathrm{mg} / \mathrm{kg}$ dose provided a non-significant decrement in serum ALT, AST and ALP levels compared to the control group ( $p>0.05$ for all parameters).

The administration of MC extract to the diabetic groups provided a significant improvement in serum ALT, AST and ALP levels compared to the control group ( $\mathrm{p}<0.01$ for all parameters).

\section{Effects of MC berries extract on liver oxidant-antioxidant status}

The oxidant-antioxidant status of the liver was evaluated by determining the levels of SOD activity, MDA and GSH levels (Table 3). The induction of DM caused a significant $(\mathrm{p}<0.001)$ elevation in MDA and a significant decrement in both SOD and GSH in the diabetic model (diabetic control) group compared to the control group $(\mathrm{p}<0.001)$. There were no significant differences in terms of SOD activity, GSH and MDA levels in the MC treated $(1000 \mathrm{mg} / \mathrm{kg}$ ) group compared to the control group ( $p>0.05$ for all parameters).

Oral administration of MC berries extract improved oxidative stress as manifested by the significant increment in SOD and GSH ( $<<0.01$ for both parameters) and the significant decrement in MDA levels in the diabetic model (diabetic control) group compared to the control group. This antioxidant activity was dosedependent and found to be highest at the $1000 \mathrm{mg} / \mathrm{kg}$ dose of MC aqueous extract (Table 3).

Table 1. Effects of Myrtus communis L. berries on blood glucose levels

\begin{tabular}{|l|l|l|}
\hline Groups & $\begin{array}{l}\text { Blood glucose level before } \\
\text { MC administration } \\
(\mathbf{m g} / \mathbf{d L})\end{array}$ & $\begin{array}{l}\text { Blood glucose level after } \\
\text { MC administration } \\
\text { (mg/dL) }\end{array}$ \\
\hline Control $(\mathbf{n = 5})$ & $79.80 \pm 2.39$ & $80.40 \pm 2.02$ \\
\hline Diabetic control (n=5) & $274.4 \pm 10.36$ & $364.80 \pm 35.33^{*}$ \\
\hline MC 1000 $\mathbf{~ m g / k g ~ ( n = 5 ) ~}$ & $83.80 \pm 8.04$ & $83.80 \pm 8.23$ \\
\hline DM+ MC 250 $\mathbf{~ m g / k g ~ ( n = 5 ) ~}$ & $313.40 \pm 23.90$ & $217.87 \pm 16.42^{*}$ \\
\hline DM+ MC 500 $\mathbf{~ m g / k g ~ ( n = 5 ) ~}$ & $310.20 \pm 38.77$ & $194.40 \pm 5.13^{*}$ \\
\hline DM+ MC 1000 $\mathbf{~ m g / k g ~ ( n = 5 ) ~}$ & $329.00 \pm 27.60$ & $176.80 \pm 6.22^{* *}$ \\
\hline
\end{tabular}

Results are mean \pm SD. MC: Myrtus communis L aqueous extract, DM: Diabetic rats, comparisons: before MC administration $v s$ after $\mathrm{MC}$ administration *: $\mathrm{p}<0.05, * *$ : $\mathrm{p}<0.001$

Table 2. Effects of Myrtus communis L. berries on serum ALT, AST and ALP levels

\begin{tabular}{|l|l|l|l|}
\hline Groups & $\begin{array}{l}\text { ALT } \\
\text { (IU/L) }\end{array}$ & $\begin{array}{l}\text { AST } \\
\text { (IU/L) }\end{array}$ & $\begin{array}{l}\text { ALP } \\
\text { (IU/L) }\end{array}$ \\
\hline Control (n=5) & $27.04 \pm 2.18^{* *}$ & $60.56 \pm 2.39^{* *}$ & $81.86 \pm 8.21^{* *}$ \\
\hline Diabetic control (n=5) & $88.66 \pm 1.71$ & $148.76 \pm 5.26$ & $193.32 \pm 4.49$ \\
\hline MC 1000 mg/kg (n=5) & $16.96 \pm 1.78^{* *}$ & $48.64 \pm 2.44^{* *}$ & $76.38 \pm 6.96^{* *}$ \\
\hline DM+ MC 250 mg/kg (n=5) & $80.00 \pm 1.15^{* *}$ & $128.34 \pm 2.93^{* *}$ & $173.84 \pm 3.37^{* *}$ \\
\hline DM+ MC 500 mg/kg (n=5) & $62.98 \pm 1.82^{* *}$ & $109.64 \pm 1.75^{* *}$ & $155.72 \pm 3.90^{* *}$ \\
\hline DM+ MC 1000 mg/kg (n=5) & $32.26 \pm 1.56^{* *}$ & $79.96 \pm 2.62^{* *}$ & $132.36 \pm 1.85^{* *}$ \\
\hline
\end{tabular}

Results are mean \pm SD. MC: Myrtus communis L aqueous extract, DM: Diabetic rats, comparisons: diabetic control group $v s$ other groups, *:p<0.05, **: $\mathrm{p}<0.001$

Table 3. Effects of Myrtus communis L. berries on liver tissue SOD activity and GSH, MDA levels

\begin{tabular}{|l|l|l|l|}
\hline Groups & $\begin{array}{l}\text { SOD } \\
\text { (U/mg tissue) }\end{array}$ & $\begin{array}{l}\text { GSH } \\
(\square \mathbf{M} / \mathbf{m g} \text { tissue) }\end{array}$ & $\begin{array}{l}\text { MDA } \\
\text { ( } \square \mathbf{M} / \mathbf{m g} \text { tissue) }\end{array}$ \\
\hline Control (n=5) & $13.94 \pm 1.08^{* *}$ & $2.79 \pm 0.09^{* * *}$ & $23.54 \pm 0.97^{* *}$ \\
\hline Diabetic control $(\mathbf{n = 5})$ & $8.67 \pm 0.63$ & $1.82 \pm 0.21$ & $33.96 \pm 1.01$ \\
\hline
\end{tabular}


Antioxidant and Antidiabetic Activity of Aqueous Extract of Myrtus Communis L. Berries on.....

\begin{tabular}{|c|c|c|c|}
\hline MC $1000 \mathrm{mg} / \mathrm{kg}(\mathrm{n}=5)$ & $14.72 \pm 0.92^{* *}$ & $2.88 \pm 0.09^{* *}$ & $21.79 \pm 1.03^{* *}$ \\
\hline DM+ MC $250 \mathrm{mg} / \mathrm{kg}(\mathrm{n}=5)$ & $9.76 \pm 1.33$ & $2.09 \pm 0.03^{*}$ & $30.71 \pm 0.59^{* *}$ \\
\hline DM+ MC $500 \mathrm{mg} / \mathrm{kg}(\mathrm{n}=5)$ & $10.80 \pm 1.85^{*}$ & $2.19 \pm 0.06^{* *}$ & $28.03 \pm 0.48^{* *}$ \\
\hline DM+ MC 1000 mg/kg $(n=5)$ & $12.62 \pm 1.08^{* * *}$ & $2.37 \pm 0.11^{* *}$ & $25.79 \pm 0.70^{* *}$ \\
\hline
\end{tabular}

Results are mean $\pm \mathrm{SD}$, MC: Myrtus communis L aqueous extract, DM: Diabetic rats, comparisons: diabetic control group $v s$ other groups, *:p<0.05, **: $\mathrm{p}<0.001$

\section{Discussion}

Changes in carbohydrate, lipid, and protein metabolisms related to DM lead to disorders in many organs and metabolisms ${ }^{10}$. Liver disease prevalance in DM patients is high ${ }^{11}$. Although the underlying mechanism is not clear, it is known that there is a relationship between insulin signaling and hepatocellular damage $^{12}$. Altered blood glucose levels may cause inequality in redox reactions ${ }^{13}$. It is also known that STZ has adverse effects on the liver ${ }^{14,15}$. Histopathological studies have demonstrated that the liver was necrotized in diabetic rats ${ }^{16}$.

ALT, AST and ALP are liver enzymes and the altered serum levels of these enzymes arises from a possible leakage of enzymes from hepotocytes into the blood stream. Therefore, elevated serum AST, ALT and ALP levels are considered a sign of hepatic injury ${ }^{17-19}$.

In the current study, MC administration provided a significant decrease in the AST, ALT and ALP activities of diabetic rats, as has been previously reported ${ }^{20,21}$. It is presumed that MC extract prevented hepatocellular damage by avoiding leakage of the enzymes from hepatocytes to the blood stream.

Blood glucose level is the most used diagnostic criteria for diabetes ${ }^{22}$. Previous studies have demonstrated the hypoglycemic effects of ethanol-water extract of MC and the phenolic compounds extracted from $\mathrm{MC}^{6,23}$. It should be noted that, these studies reported the hypoglycemic effects of MC extract and its components only on diabetic animals, and the extract and its components did not show any hypoglycemic effects on normoglycemic animals ${ }^{6}$. Similar to these studies, the results of the current study showed that although there was a slight alteration in the blood glucose level in the MC extract $1000 \mathrm{mg} / \mathrm{kg}$ group, compared to the normal control group, this alteration was not significant. The administrated doses of MC showed a hypoglycemic effect in diabetic rats ,being highest at the dose of $1000 \mathrm{mg} / \mathrm{kg}$. This dose value was close to previously reported effective doses of extracts and compounds of MC. Future studies will be conducted on doses close to $1000 \mathrm{mg} / \mathrm{kg}$ to determine the accurate hypoglycemic dose of MC berries.

It is known that production of reactive oxygen species (ROS) as a result of oxidative stress accompanies DM due to the auto-oxidation of excessive glucose ${ }^{24}$. In fact, there is considerable evidence about the oxidative stress inducing potential of $\mathrm{STZ}^{25}$. Once excessive free radicals are formed, they diffuse into cells and form mitochondrial enzyme injury and DNA fragmentations, which lead to cellular damage and complications of $\mathrm{DM}^{26}$. Supporting these findings, approaches aiming to treat DM complications with antioxidant molecules and plants are based on the oxidative stress mechanism of $\mathrm{DM}^{27,28}$. GSH is a key element of the non-enzymatic antioxidant system. Diminished levels of GSH may be a result of either a reduction in its synthesis or of oxidative stress. SOD is an enzymatic antioxidant which protects cells from oxidative injury generated by $\operatorname{ROS}^{29}$. Lipid peroxides in the cellular membrane are metabolized to MDA in $\beta$-oxidation reactions. Elevated serum MDA levels are considered to be an indicator of cellular membrane injury caused by oxidative stress ${ }^{30}$.

Many studies have reported on diminished enzymatic and non-enzymatic antioxidant activities in diabetic rats ${ }^{31,32}$. Oxidative stress resulting from excessive production of ROS has been suggested to be a potential mechanism involved in diabetic hepatopathy ${ }^{32}$ and other complications ${ }^{33,34}$. In the current study, the administration of aqueous extract of MC berries provided a significant improvement in the antioxidant system, namely an increment in SOD activity and GSH levels and a reduction in MDA levels. Considering that MC extract is a rich source of polyphenolic compounds which have inhibitor potential of glucose absorption from the intestines ${ }^{35,36}$, it can be concluded that the antidiabetic effect of MC is based on its hypoglycemic and antioxidant properties.

In conclusion, the results of this study demonstrated that MC extract provided significant hypoglycemic and antioxidant effects on diabetic rats. It must be considered that the extract had no hypoglycemic and antioxidant effect on normoglycemic rats. Thus, the use of MC berries can be recommended complementary to antidiabetic treatment in DM patients, rather than dietary consumption of the plant by individuals at risk of DM. It is clear that the consumption of berries is more practical than the use of volatile oil or extracts of leaves which require some pre-processing steps. This preliminary study can be considered useful as guidance for further studies including SOD expression levels and those studies could help to create an antidiabetic agent from MC.

\section{Conflict of Interest}


The authors declare that there is no conflict of interest.

\section{Acknowledgment}

This study was supported by the Scientific Research Projects Unit of Ataturk University (BAP, project no. 2009/314).

\section{References}

[1] American Diabetes Association. Diagnosis and classification of diabetes mellitus. Diabetes Care 37(1), 2014, 81-90.

[2] Pitkänen OM, Martin JM, Hallman M, Akerblom HK, Sariola H, Andersson SM.Free radical activity during development of insulin-dependent diabetes mellitus in the rat. Life Sci 50(5), 1992, 335-339.

[3] Dey A, Lakshmanan J.The role of antioxidants and other agents in alleviating hyperglycemia mediated oxidative stress and injury in liver. Food Funct 4(8), 2013, 1148-1184.

[4] Sepici A, Gürbüz I, Cevik C, Yesilada E. Hypoglycaemic effects of myrtle oil in normal and alloxan-diabetic rabbits. $J$ Ethnopharmacol 93(2-3), 2004, 311-318.

[5] Alipour G, Dashti S, Hosseinzadeh H. Review of pharmacological effects of Myrtus communis L. and its active constituents. Phytother Res 28(8), 2014, 1125-1136.

[6] Elfellah MS, Akhtar MH, Khan MT.Anti-hyperglycaemic effect of an extract of Myrtus communis in streptozotocin-induced diabetes in mice. J Ethnopharmacol 11(3), 1984, 275-281.

[7] Sepici-Dincel A, Açıkgoz S, Cevik C, Sengelen M, Yesilada E. Effects of in vivo antioxidant enzyme activities of myrtle oil in normoglycaemic and alloxan diabetic rabbits. J Ethnopharmacol 110, 2007, 498-503.

[8] Ademiluyi AO, Oboh G. Attenuation of oxidative stress and hepatic damage by some fermented tropical legume condiment diets in streptozotocin-induced diabetes in rats. Asian Pac J Trop Med 5(9), 2012, 692-697.

[9] Sedlak J, Lindsay RH. Estimation of total, protein-bound, and nonprotein sulfhydryl groups in tissue with Ellman's reagent. Analytical Biochemistry 25, 1968, 192-205.

[10] Tanaka K, Nanbara S, Tanaka T, Koide H, Hayashi T. Aminotransferase activity in the liver of diabetic mice. Diabetes Res Clin Pract 5(1), 1988, 71-75.

[11] Tolman KG, Fonseca V, Dalpiaz A, Tan MH. Spectrum of liver disease in type 2 diabetes and management of patients with diabetes and liver disease. Diabetes Care 30(3), 2007, 734-743.

[12] Kohl T, Gehrke N, Schad A, Nagel M, Wörns MA, Sprinzl MF et al. Diabetic liver injury from streptozotocin is regulated through the caspase-8 homolog cFLIP involving activation of JNK2 and intrahepatic immunocompetent cells. Cell Death Dis 2013 4;4:e712. doi: 10.1038/cddis.2013.228.

[13] Cameron NE, Gibson TM, Nangle MR, Cotter MA. Inhibitors of advanced glycation end product formation and neurovascular dysfunction in experimental diabetes. Ann NY Acad Sci 1043, 2005, 784-792.

[14] Giannini EG, Testa R, Savarino V. Liver enzyme alteration: a guide for clinicians. CMAJ 2005;172:367-379.

[15] Ashraf H, Heidari R, Nejati V, Ilkhanipoor M. Aqueous extract of Berberis integerrima root improves renal dysfunction in streptozotocin induced diabetic rats. AJP Avicenna J Phytomed 3, 2013, 82-90.

[16] Larcan A, Lambert H, Laprevote-Heully MC, Delorme N. Light and electron microscopic study of hepatic lesions in the course of hyperlactatemia in diabetic patients (author's transl). Diabete Metab 5(2), 1979, 103-112.

[17] Schneider AL, Lazo M, Ndumele CE, Pankow JS, Coresh J, Clark JM et al. Liver enzymes, race, gender and diabetes risk: the Atherosclerosis Risk in Communities (ARIC) Study. Diabet Med 30(8), 2013, 926-933.

[18] De Ritis F, Coltorti M, Giusti G.Serum-transaminase activities in liver disease. Lancet 1(7752), 1972, 685-687.

[19] Nannipieri M, Gonzales C, Baldi S, Posadas R, Williams K, Haffner SM et al.; Mexico City diabetes study. Liver enzymes, the metabolic syndrome, and incident diabetes: the Mexico City diabetes study. Diabetes Care 28(7), 2005, $1757-1762$.

[20] Kharroubi AT, Darwish HM. Diabetes mellitus: The epidemic of the century. World J Diabetes 6(6), $2015,850-867$.

[21] Rai PK, Mehta S, Watal G. Hypolipidaemic and hepatoprotective effects of Psidium guajava raw fruit peel in experimental diabetes. Indian J Med Res 131, 2010, 820-824.

[22] [222006. $\quad$ pp. 1-46. Report of a $\quad$ WHO/IDF at http://apps.who.int/iris/bitstream/10665/43588/1/9241594934_eng.pdf Last accessed 26 August 2015.

[23] Benkhayal FA, Musbah E-G, Ramesh S, Dhayabaran D. Biochemical studies on the effect of phenolic compounds extracted from Myrtus communis in diabetic rats. Tamilnadu J Vet Anim Sci 5, 2009, 87-93

[24] Boynes JW. Role of oxidative stress in development of complication in diabetes. Diabetes 40, 191, 405-411.

[25] Szkudelski T. The mechanism of alloxan and streptozotocin action in B cells of the rat pancreas. Physiol Res 50, 2001, 537-546

[26] Bonnefont-Rousselot D, Bastard JP, Jaudon MC, Delattre J. Consequences of the diabetic status on the oxidant/antioxidant balance. Diabetes Metab 26, 2000, 163-176.

[27] Siman CM, Eriksson UJ. Vitamin E decreases the occurrence of malformations in the offspring of diabetic rats. Diabetes 46, 1997, 1054-1061.

[28] Rodrigues GR, Di Naso FC, Porawski M, Marcolin E, Kretzmann NA, Ferraz Ade B et al.Treatment with aqueous extract from Croton cajucara Benth reduces hepatic oxidative stress in streptozotocin-diabetic rats. J Biomed Biotechnol 2012, 902351

[29] Evan G, Littlewood TA. Matter of life and cell death. Science 28, 1998, 1317

[30] Ayala A, Muñoz MF, Arguelles S. Lipid peroxidation: production, metabolism, and signaling mechanisms of malondialdehyde and 4-hydroxy-2-nonenal. Oxid Med Cell Longev 2014, 2014,360438.

[31] Miyazaki Y, Kawano H, Yoshida T, Miyamoto S, Hokamaki J,Nagayoshi Y et al. Pancreatic B-cell function is altered by oxidative stress induced by acute hyperglycaemia. Diabet Med 24, 2007, 154-160

[32] Abolfathi AA, Mohajeri D, Rezaie A, Nazeri M. Protective Effects of Green Tea Extract against Hepatic Tissue Injury in Streptozotocin-Induced Diabetic Rats. Evid Based Complement Alternat Med 2012,2012, 740671. doi: 10.1155/2012/740671. Epub 2012 Feb 27.

[33] Curcio F, Pegoraro I, DelloRusso P, Falleti E, Perrella A. Ceriello A. SOD and GSH inhibit the high glucose-induced oxidative damage and the PDGF increased secretion in cultured human endothelial cells. Thrombosis and Haemostasis 1995; 74(3):969-973.

[34] Kakkar R, Kalra J, Mantha SV, Prasad K. Lipid peroxidation and activity of antioxidant enzymes in diabetic Rats. Molecular and Cellular Biochemistry 151(2), 1995, 113-119.

[35] Vessal M, Hemmati M, Vasei M. Antidiabetic effects of quercetin in streptozocin-induced diabetic rats. Comp Biochem Physiol C Toxicol Pharmacol 135C(3), 2003, 357-364. 
Antioxidant and Antidiabetic Activity of Aqueous Extract of Myrtus Communis L. Berries on.....

[36] Song J, Kwon O, Chen S, Daruwala R, Eck P, Park JB et al. Flavonoid inhibition of sodium-dependent vitamin C transporter 1 (SVCT1) and glucose transporter isoform 2 (GLUT2), intestinal transporters for vitamin C and Glucose. J Biol Chem 277(18), 2002, 15252 . 